\title{
Aplikasi Sistem Informasi Ketersediaan Ruang Rawat dan Ketersediaan Darah (SIDARURAT) di Kabupaten Pekalongan
}

\author{
Mokhamad Arifin ${ }^{1 *}$, Irnawati ${ }^{2}$ \\ ${ }^{1,2}$ Prodi Sarjana Keperawatan, STIKES Muhammadiyah Pekajangan Pekalongan \\ *Email: arifin_pkj@yahoo.co.id
}

Kata Kunci
Aplikasi
Kesehatan
Seluler,
siDARURAT,
Sistem
Informasi

\begin{abstract}
Abstrak
Kondisi yang mendesak misalnya gagal jantung, gagal nafas, perdarahan post partum, eklamsia atau kondisi yang mengancam nyawa lainya membuat tenaga kesehatan, pasien dan keluarga pasien sangat ingin segera mendapat informasi rumah sakit tentang ketersediaan ruang rawat dan ketersediaan darah. Teknologi yang diterapkan pada perangkat seluler dapat menjadi strategi penting dalam program penyediaan informasi ketersediaan ruang rawat dan ketersediaan darah. Penelitian ini bertujuan untuk membuat aplikasi ketersediaan ruang rawat dan ketersediaan darah (siDARURAT). Penelitian ini menggunakan desain penelitian Waterfall dengan uji black box.Hasil penelitian ini yaitu terbentuk aplikasi siDARURAT yang dapat digunakan melalui smartphone atau komputer, dan fungsi dalam sistem, baik form maupun tombol-tombol yang ada telah berjalan sesuai fungsinya berdasarkan pengujian black box. Agar aplikasi ini lebih maksimal, diharapkan rumah sakit dan PMI secara rutin mengupdate data ketersediaan ruang rawat dan ketersediaan darah.
\end{abstract}

\section{App Information System of Availability of Inpatient Wards and Blood Donors Pact Availability (Sidarurat) in Pekalongan Regency}

Key Words:

Mobile Health

Application, SiDARURAT, Information System

\begin{abstract}
Urgent conditions such as heart failure, respiratory failure, postpartum hemorrhage, eclampsia or other life-threatening conditions make healthcare workers, patients and families desperate to get hospital information about the rooming space availability and availability blood. The technology applied to mobile devices can be an important strategy in the provision of information on rooming space availability and the availability of blood. The aim at this study to make the application rooming space availability and availability of blood (SiDARURAT). This research used Waterfall research design with black box test. The result of this research is formed by the application of SiDARURAT which can be used through smartphone or computer, and the function in the system, both form and the buttons that have been running according to its function based on black box testing. In order for this application more leverage, hospital and PMI are expected to regularly update the data availability of care and availability of blood.
\end{abstract}

\section{PENDAHULUAN}

Salah satu tantangan utama dalam memenuhi kebutuhan masyarakat yang kekurangan sumber daya adalah akses ke perawatan kesehatan yang berkelanjutan dan adil. Organisasi Kesehatan Dunia telah mengidentifikasi telemedicine sebagai salah satu solusi potensial untuk mengatasi kesenjangan dalam distribusi kesehatan, dan untuk memfasilitasi dan mening- katkan manajemen klinis, pendidikan dan penelitian. Saat ini ada banyak bukti untuk keberhasilan penerapan teknologi telemedicine secara umum di seluruh spektrum spesialisasi medis. Berbagai format telah digunakan, termasuk konferensi video real-time, telemedicine seluler atau seluler, sistem hibrida dan model terintegrasi (Segato \& Masella, 2017). 
PROFESI (Profesional Islam): Media Publikasi Penelitian

2019; Volume 16; No 2.

Website: ejournal.stikespku.ac.id

Teknologi telemedicine memiliki kemampuan untuk menangkap gambar, menyimpannya untuk sementara, mengirimnya ke atau dari lokasi terpencil, dan memfasilitasi tampilan gambar, dengan kehilangan resolusi yang minimal. Beberapa metode ini membutuhkan infrastruktur fisik dan personel tetap, aman, dan terbukti cukup mahal (Miah, et al., 2017). Jumlah aplikasi medis telah sangat meningkat selama satu dekade terakhir. Pada 2012, ada lebih dari 13.000 aplikasi yang terkait dengan perawatan kesehatan yang tersedia untuk pengguna Apple iPhone dan lebih dari 6.000 tersedia di Android Store (Pai \& Alathur, 2018).

Kemajuan dalam bidang teknologi informasi dan peningkatan penggunaan internet telah mengubah kehidupan orang-orang dengan meamungkinkan berbagai layanan online. Belakangan ini, sektor kesehatan yang menghadapi tantangan layanannya mulai mempromosikan dan menggunakan kesehatan seluler (Sahay, et al,. 2018). Masyarakat belum tahu mengenai sistem rujukan. Inilah yang menjadi persoalan, ketika sudah datang ke rumah sakit tersier pasien akan dilayani jika sudah mendapatkan rujukan dari pelayanan kesehatan primer. Sistem rujukan sudah diatur dalam Peraturan Menteri Kesehatan No. 001/ 2012 Tentang Sistem Rujukan Pelayanan Kesehatan Perorangan (PMK) (Kemenkes, 2013).

Masyarakat belum tahu mengenai sistem rujukan. Inilah yang menjadi persoalan, ketika sudah datang ke rumah sakit tersier pasien akan dilayani jika sudah mendapatkan rujukan dari peyanan kesehatan primer. Sistem rujukan sudah diatur dalam Peraturan Menteri Kesehatan No. 001/2012 Tentang Sistem Rujukan Pelayanan Kesehatan Perorangan (PMK) (Kemenkes, 2013).

Sistem rujukan diharapkan semua memperoleh keuntungan. Misalnya, pemerintah sebagai penentu kebijakan kesehatan (policy maker), manfaat yang akan diperoleh di antaranya, membantu penghematan dana dan memperjelas sistem pelayanan kesehatan. Bagi masyarakat sebagai pemakai jasa pelayanan akan meringankan biaya pengobatan karena pelayanan yang diperoleh sangat mudah. Bagi pelayanan kesehatan (health provider), mendorong jenjang karier tenaga kesehatan, selain meningkatkan pengetahuan maupun keterampilan, serta meringankan beban tugas (Kemenkes, 2013).
Darah merupakan salah satu komponen pada tubuh manusia yang memiliki peranan sangat penting. Fungsi utama darah adalah sebagai alat transportasi. Seperti organ vital lainnya, darah dapat didonorkan kepada mereka yang membutuhkan melalui proses transfusi darah. Transfusi darah secara universal dibutuhkan untuk menangani pasien anemia berat, pasien dengan kelainan darah bawaan, pasien yang mengalami kecederaan parah, pasien yang hendak menjalankan tindakan bedah operatif dan pasien yang mengalami penyakit liver ataupun penyakit lainnya yang mengakibatkan tubuh pasien tidak dapat memproduksi darah atau komponen darah sebagaimana mestinya. Tanpa darah yang cukup, seseorang dapat mengalami gangguan kesehatan bahkan kematian (Depkes RI, 2008).

Pelayanan transfusi darah merupakan upaya pelayanan kesehatan yang terdiri dari serangkaian kegiatan mulai dari ajakan untuk melakukan donor darah, pengambilan, pengamanan, pengolahan, penyimpanan darah dan tindakan medis pemberian darah kepada resipien untuk tujuan penyembuhan penyakit dan pemulihan kesehatan (Depkes RI, 2008).

Kebutuhan akan darah tidak mengenal waktu, 24 jam sehari bahkan dikala liburpun harus disiagakan, sehingga informasi terbuka akan ketersediaan darah menjadi sangat penting. Dimana melalui Peraturan Pemerintah No. 7 tahun 2011, PMI sebagai organisasi sosial masyarakat dibidang kemanusiaan dipercaya oleh Pemerintah Republik Indonesia untuk melakukan pembinaan dan pengawasan dalam pengelolaan pelayanan darah melalui Unit Donor Darah (UDD). Dengan adanya peraturan ini pula disempurnakan bahwa pelayanan darah menjadi tugas Pemerintah Pusat dan Pemerintah Daerah. PMI dalam mendukung pemerintah dengan segala sumberdaya berusaha melaksanakan amanah tersebut bekerja sama dengan instansi terkait di pemerintahan pusat dan daerah (Setiawan, 2012).

Saat ini, telah ada program SIJARIEMAS yang ditujukan dalam menekan angka kematian ibu dan anak, penggunaannya lebih dikhususkan pada kasus-kasus obststrik dan neonatus dengan akses yang terbatas antar fasilitas kesehatan dan belum open source. Program ini masis berbasis SMS gateway dan call center dimana tiap rumah sakit sudah dikoneksikan dengan tenaga kesehatan. 
PROFESI (Profesional Islam): Media Publikasi Penelitian 2019; Volume 16; No 2. Website: ejournal.stikespku.ac.id

Program ini hanya dioperasikan oleh petugas baikdai puskesmas dan rumah sakit sehingga masyarakat tidak dapat secara langsung memantau kondisi ketersediaan dirumah sakit yang dibutuhkan.

Dengan latar belakang tersebut akan membuat sebuah aplikasi Sistem informasi Ketersediaan Ruang Rawat dan Ketersedian Darah (siDARURAT) di Kabupaten Pekalongan dengan Aplikasi berbasis WEB- mobile support yang mudah diakses oleh Dokter, bidan, perawat yang bekerja di level PPK1, dan masyarakat umum.

\section{METODE PENELITIAN}

Penelitian ini menggunakan metode pengembangan sistem model waterfall atau model air terjun merupakan paradigma yang tertua untuk rekayasa perangkat lunak. Model ini menggambarkan proses software development dalam aliran sekuensial linear, sehingga apabila suatu proses dalam pengembangan proyek belum terselesaikan, maka proses lain dalam proyek ini tidak dapat diselesaikan.Untuk memastikan bahwa kebutuhan fungsional dan non fungsional terpenuhi dalam implementasi sistem informasi ketersediaan ruang rawat dan ketersediaan darah (siDARURAT), maka dilakukan beberapa tahap pengujian sistem, diantaranya apakah interface berjalan sesuai harapan dengan menggunakan pengujian black box.

\section{HASIL PENELITIAN}

Program ini merupakan program berbasis WEB yang dapat di operasikan dengan Komputer Windows XP biasa minimal dengan RAM 512 dan yang juga bisa diakses dengan Smartphone Android ataupun WindowsPhone pada jaringan GSM, 3G maupun CDMA seperti Smartfren yang sudah menjangkau Kabupaten Pekalongan di daerah bawah maupun atas. Dengan fasilitas Mobile support maka tampilan di Smartphone akan lebih bagus karena akan menyesuaikan dengan kondisi layar handphone yang digunakan.

Adapun fitur-fitur yang terdapat pada aplikasi siDARURAT adalah sebagai berikut:
1. User

a. Halaman Home

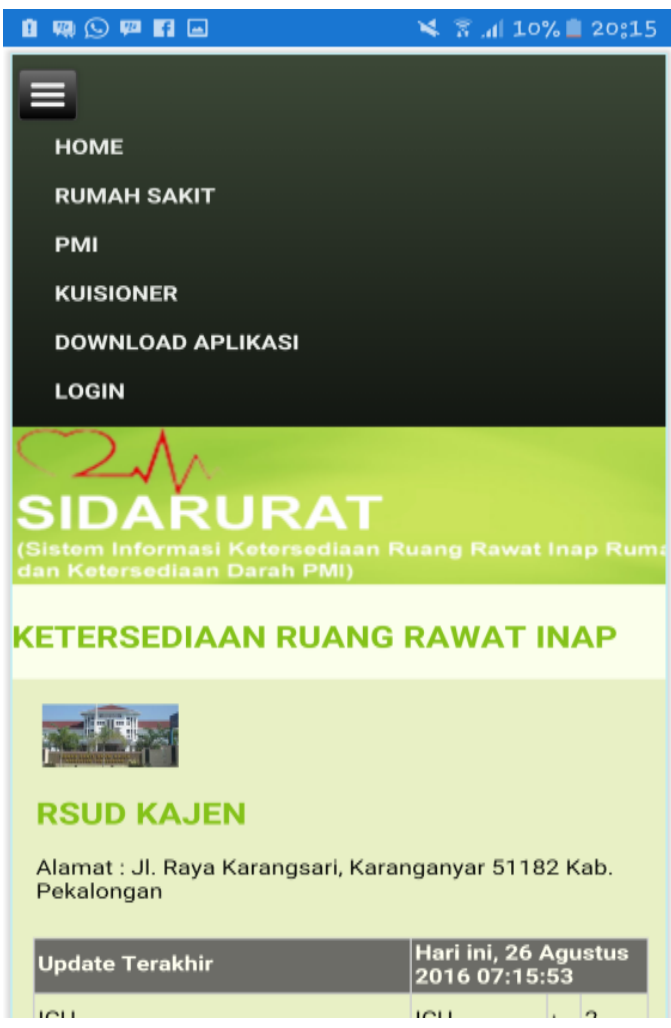

b. Halaman Rumah Sakit

\begin{tabular}{l|l|l|}
\hline RSI PKU MUHAMMADIYAH \\
PEKAJANGAN \\
Alamat: JI. Raya Ambokembang No. 42-44, Kedungwuni \\
Pekalongan
\end{tabular}


PROFESI (Profesional Islam): Media Publikasi Penelitian 2019; Volume 16; No 2.

Website: ejournal.stikespku.ac.id

\section{c. Halaman PMI}

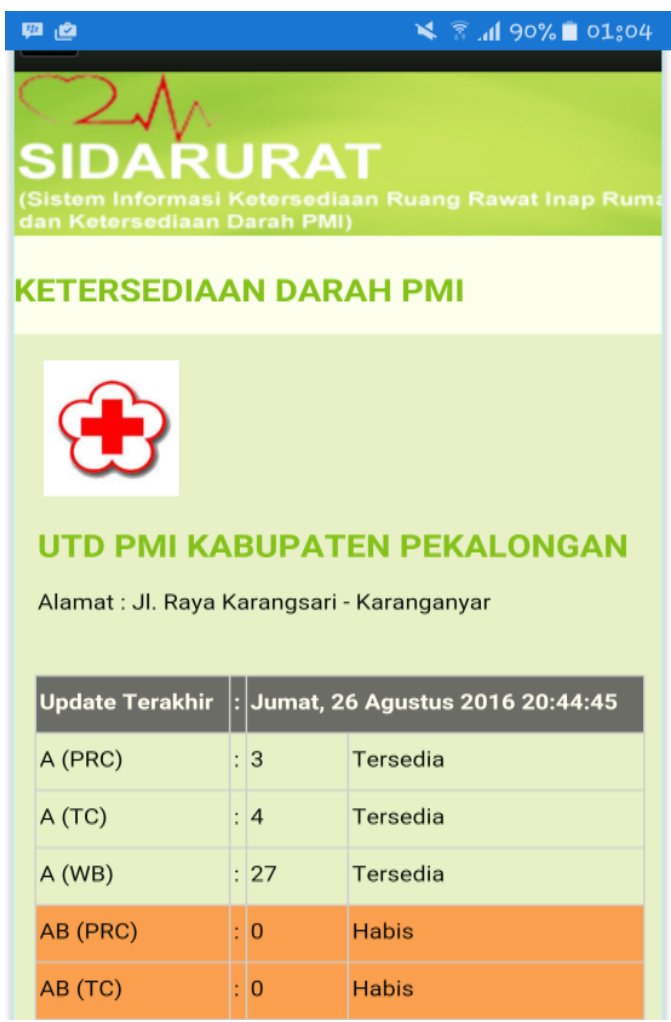

d. Halaman kuesioner

Berikan jawaban dengan meng-klik pada salah satu rentang
jawaban yang tersedia pada pernyataan dibawah ini lalu
klik kirim.
Ketika pengguna mengisi dan mengirim kuesioner ini
secara otomatis merupakan persetujuan responden.
Terima kasih atas partisipasinya.
Nama
No Hp
Instansi
Pekerjaan

\section{e. Halaman download aplikasi}

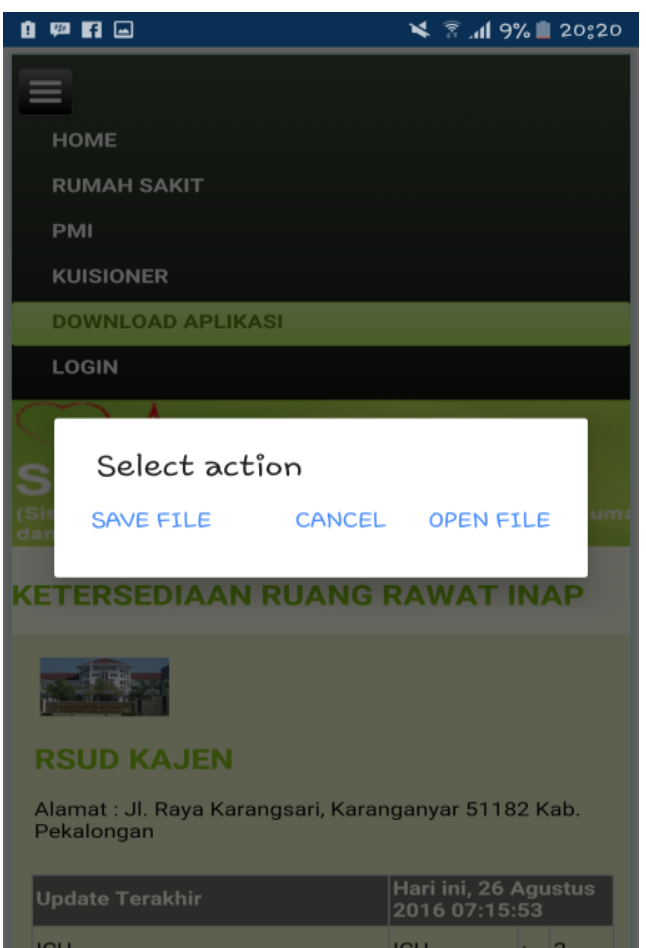

2. Administrator

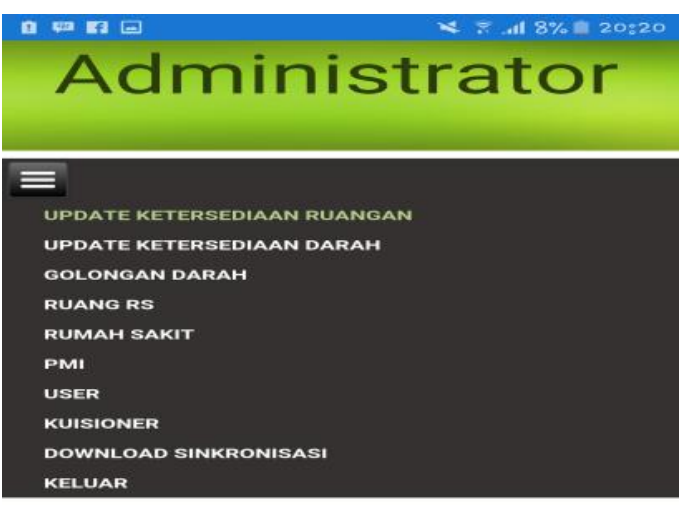

Silahkan Pilih Menu

\section{Hasil Pengujian Sistem}

Untuk memastikan bahwa kebutuhan fungsional dan non fungsional terpenuhi dalam implementasi sistem informasi ketersediaan ruang rawat dan ketersediaan darah (siDARURAT), maka dilakukan beberapa tahap pengujian sistem, diantaranya apakah interface berjalan sesuai harapan dengan menggunakan pengujian black box, dan apakah implementasi sistem sesuai dengan kebutuhan fungsional dan non fungsional menurut end user dengan menggunakan user acceptence test. 
PROFESI (Profesional Islam): Media Publikasi Penelitian 2019; Volume 16; No 2. Website: ejournal.stikespku.ac.id

a. Pengujian Black Box

1) Halaman User (Front End)

Tabel 1. Pengujian Black Box Menu Utama

\begin{tabular}{|c|c|c|c|c|}
\hline No & Test case & Hasil yang diharapkan & Hasil pengujian & Keterangan \\
\hline 1 & $\begin{array}{l}\text { User menekan } \\
\text { menu home }\end{array}$ & $\begin{array}{l}\text { Sistem akan menampilkan informasi } \\
\text { ketersediaan ruang rawat inap di } \\
\text { berbagai rumah sakit dan nomor } \\
\text { telepon rumah sakit tersebut }\end{array}$ & $\begin{array}{l}\text { Tampil informasi ketersediaan } \\
\text { ruang rawat inap baik berbagai } \\
\text { rumah sakit dan nomor telepon } \\
\text { rumah sakit tersebut }\end{array}$ & Terpenuhi \\
\hline 2 & $\begin{array}{l}\text { User menekan } \\
\text { menu rumah sakit }\end{array}$ & $\begin{array}{l}\text { Sistem akan menampilkan beberapa } \\
\text { pilihan rumah sakit }\end{array}$ & $\begin{array}{l}\text { Tampil beberapa pilihan rumah } \\
\text { sakit }\end{array}$ & Terpenuhi \\
\hline 3 & $\begin{array}{l}\text { User menekan } \\
\text { menu PMI }\end{array}$ & $\begin{array}{l}\text { Sistem akan menampilkan beberapa } \\
\text { pilihan unit transfusi darah }\end{array}$ & $\begin{array}{l}\text { Tampil beberapa pilihan unit } \\
\text { transfusi darah }\end{array}$ & Terpenuhi \\
\hline 4 & $\begin{array}{l}\text { User menekan } \\
\text { menu kuesioner }\end{array}$ & Sistem akanmenampilkan kuesioner & Tampil kuesioner & Terpenuhi \\
\hline 5 & $\begin{array}{l}\text { User menekan } \\
\text { menu download }\end{array}$ & $\begin{array}{l}\text { Menampilkan shortcut di halaman } \\
\text { menu handphone/tablet secara } \\
\text { otomatis dan menu aplikasi download } \\
\text { dapat berjalan }\end{array}$ & $\begin{array}{l}\text { Tampil shortcut di halaman } \\
\text { menu handphone/tablet secara } \\
\text { otomatis dan menu aplikasi } \\
\text { download dapat berjalan }\end{array}$ & Terpenuhi \\
\hline
\end{tabular}

Tabel 2. Pengujian Black Box Halaman Rumah Sakit

\begin{tabular}{|c|c|c|c|c|}
\hline No & Test case & Hasil yang diharapkan & Hasil pengujian & Keterangan \\
\hline 1 & $\begin{array}{l}\text { User menekan } \\
\text { menu semua RS }\end{array}$ & $\begin{array}{l}\text { Menampilkan informasi ketersediaan } \\
\text { ruang rawat inap di berbagai rumah } \\
\text { sakit beserta nomor telepon rumah } \\
\text { sakit tersebut }\end{array}$ & $\begin{array}{l}\text { Tampil informasi ketersediaan } \\
\text { ruang rawat inap di berbagai } \\
\text { rumah sakit beserta nomor } \\
\text { telepon rumah sakit tersebut }\end{array}$ & Terpenuhi \\
\hline 2 & $\begin{array}{l}\text { User menekan } \\
\text { menu RSUD } \\
\text { Kajen }\end{array}$ & $\begin{array}{l}\text { Menampilkan informasi ketersediaan } \\
\text { ruang rawat inap di RSUD Kajen } \\
\text { beserta nomor teleponnya }\end{array}$ & $\begin{array}{l}\text { Tampil informasi ketersediaan } \\
\text { ruang rawat inap di RSUD } \\
\text { Kajen beserta nomor teleponnya }\end{array}$ & Terpenuhi \\
\hline 3 & $\begin{array}{l}\text { User menekan } \\
\text { menu RSI PKU } \\
\text { Muhammadiyah } \\
\text { Pekajangan }\end{array}$ & $\begin{array}{l}\text { Menampilkan informasi ketersediaan } \\
\text { ruang rawat inap di RSI PKU } \\
\text { Muhammadiyah Pekajangan beserta } \\
\text { nomor teleponnya }\end{array}$ & $\begin{array}{l}\text { Tampil informasi ketersediaan } \\
\text { ruang rawat inap di RSI PKU } \\
\text { Muhammadiyah Pekajangan } \\
\text { beserta nomor teleponnya }\end{array}$ & Terpenuhi \\
\hline 4 & $\begin{array}{l}\text { User menekan } \\
\text { menekan menu } \\
\text { RSUD Kraton }\end{array}$ & $\begin{array}{l}\text { Menampilkan informasi ketersediaan } \\
\text { ruang rawat inap di RSUD Kraton }\end{array}$ & $\begin{array}{l}\text { Tampil informasi ketersediaan } \\
\text { ruang rawat inap di RSUD } \\
\text { Kraton }\end{array}$ & Terpenuhi \\
\hline
\end{tabular}

Tabel 3. Pengujian Black Box PMI

\begin{tabular}{|c|c|c|c|c|}
\hline No & Test case & Hasil yang diharapkan & Hasil pengujian & $\begin{array}{c}\text { Keteranga } \\
n\end{array}$ \\
\hline 1 & $\begin{array}{l}\text { User menekan } \\
\text { menu semua PMI }\end{array}$ & $\begin{array}{l}\text { Menampilkan informasi ketersediaan } \\
\text { darah PMI di berbagai Unit Transfusi } \\
\text { Darah beserta nomor telepon unit } \\
\text { tersebut }\end{array}$ & $\begin{array}{l}\text { Tampil informasi ketersediaan } \\
\text { darah PMI di berbagai Unit } \\
\text { Transfusi Darah beserta nomor } \\
\text { telepon unit tersebut }\end{array}$ & Terpenuhi \\
\hline 2 & $\begin{array}{l}\text { User menekan } \\
\text { menu UTD PMI } \\
\text { Kabupaten } \\
\text { Pekalongan }\end{array}$ & $\begin{array}{l}\text { Menampilkan informasi ketersediaan } \\
\text { darah PMI di UTD PMI Kabupaten } \\
\text { Pekalongan beserta nomor telepon } \\
\text { unit tersebut }\end{array}$ & $\begin{array}{l}\text { Tampil informasi ketersediaan } \\
\text { ketersediaan darah PMI di UTD } \\
\text { PMI Kabupaten Pekalongan be- } \\
\text { serta nomor telepon unit tersebut }\end{array}$ & Terpenuhi \\
\hline 3 & $\begin{array}{l}\text { User menekan } \\
\text { menu bank darah } \\
\text { RSUD Kraton }\end{array}$ & $\begin{array}{l}\text { Menampilkan informasi ketersediaan } \\
\text { darah PMI di bank darah RSUD } \\
\text { Kraton beserta nomor teleponnya }\end{array}$ & $\begin{array}{l}\text { Tampil informasi ketersediaan } \\
\text { darah PMI di bank darah RSUD } \\
\text { Kraton beserta nomor } \\
\text { teleponnya }\end{array}$ & Terpenuhi \\
\hline
\end{tabular}


PROFESI (Profesional Islam): Media Publikasi Penelitian

2019; Volume 16; No 2.

Website: ejournal.stikespku.ac.id

Tabel 4. Pengujian Black Box Halaman Utama Administrator

\begin{tabular}{cllll}
\hline No & \multicolumn{1}{c}{ Test case } & \multicolumn{1}{c}{ Hasil yang diharapkan } & \multicolumn{1}{c}{ Hasil pengujian } & Keterangan \\
\hline 1 & Admin menekan & Menampilkan halaman menu rumah \\
menu halaman awal & sakit dan ketersediaan ruang rawat & Tampil halaman menu rumah & Terpenuhi \\
(home) pada & inap melebar sesuai layar PC & sakit dan ketersediaan ruang & \\
penggunaan & & & rawat inap melebar sesuai \\
layar PC
\end{tabular}

Personal Computer

(PC)

2 Admin menekan menu halaman awal (home) pada penggunaan ponsel (mobile support)

3 Admin memilih menu PMI

4 Admin memilih icon telepon

5 Admin memilih menu home

6 Admin memilih menu rumah sakit

7 Admin memilih menu PMI

8 Admin memilih menu download aplikasi

9 Admin memilih menu login

10 Admin memilih menu login dengan menginput sesuai username dan password yang diberikan

11 Admin memilih menu login dengan menginput username dan password yang benar

12 Admin memilih menu login dengan menginput username dan password yang benar

13 Admin memilih menu update ketersediaan ruang rawat

14 Admin memilih menu update ketersediaan darah
Menampilkan halaman menu rumah sakit dan ketersediaan ruang rawat inap memanjang ke bawah sesuai posisi layar ponsel (mobile support)

Menampilkan halaman ketersediaan darah

Menampilkan icon tombol telepon sudah berjalan dengan baik Menampilkan halaman utama

Menampilkan data ketersediaan ruang rawat di semua dan setiap rumah sakit

Menampilkan data ketersediaan darah Tampil data ketersediaan di semua dan setiap UUD PMI

Menampilkan shortcut di halaman menu handphone/tablet secara otomatis dan menu aplikasi download secara otomatis dan menu dapat berjalan

Menampilkan isian username dan password Menampilkan halaman administrator/ operator dengan menunya

Menampilkan halaman administrator/ operator dengan menunya

Menampilkan pesan peringatan

Menampilkan form untuk merubah dan menyimpan data ketersediaan ruang rawat

Menampilkan form untuk merubah dan menyimpan data ketersediaan darah
Tampil halaman menu rumah sakit dan ketersediaan ruang rawat inap melebar sesuai posisi layar ponsel (mobile support)

Tampil halaman ketersediaan darah

Tampil icon tombol telepon sudah berjalan dengan baik Tampil halaman utama

Tampil data data ketersediaan ruang rawat di semua dan setiap rumah sakit darah di semua dan setiap UUD PMI Tampil shortcut di halaman menu handphone/tablet aplikasi download dapat berjalan

Tampil isian username dan password

Tampil halaman administrator/ operator dengan menunya

Tampil halaman administrator/ operator dengan menunya

Terpenuhi

Terpenuhi

Terpenuhi

Terpenuhi

Terpenuhi

Terpenuhi

Terpenuhi

Terpenuhi

Terpenuhi

Tampil pesan peringatan

Terpenuhi

Tampil form untuk merubah

Terpenuhi

dan menyimpan data

ketersediaan ruang rawat

Tampil form untuk merubah dan menyimpan data

Terpenuhi 
PROFESI (Profesional Islam): Media Publikasi Penelitian 2019; Volume 16; No 2.

Website: ejournal.stikespku.ac.id

\begin{tabular}{|c|c|c|c|c|}
\hline No & Test case & Hasil yang diharapkan & Hasil pengujian & Keterangan \\
\hline 15 & $\begin{array}{l}\text { Admin memilih } \\
\text { menu data rumah } \\
\text { sakit }\end{array}$ & $\begin{array}{l}\text { Menampilkan form untuk menambah } \\
\text { dan mengedit data rumah sakit }\end{array}$ & $\begin{array}{l}\text { Tampil form untuk menam- } \\
\text { bah dan mengedit data rumah } \\
\text { sakit }\end{array}$ & Terpenuhi \\
\hline 16 & $\begin{array}{l}\text { Admin memilih } \\
\text { menu PMI }\end{array}$ & $\begin{array}{l}\text { Menampilkan form untuk menambah } \\
\text { dan mengedit data PMI }\end{array}$ & $\begin{array}{l}\text { Tampil form untuk menam- } \\
\text { bah dan mengedit data PMI }\end{array}$ & Terpenuhi \\
\hline 17 & $\begin{array}{l}\text { Admin memilih } \\
\text { menu golongan } \\
\text { darah }\end{array}$ & $\begin{array}{l}\text { Menampilkan form untuk menambah } \\
\text { dan mengedit data golongan darah }\end{array}$ & $\begin{array}{l}\text { Tampil form untuk } \\
\text { menambah dan mengedit data } \\
\text { golongan darah }\end{array}$ & Terpenuhi \\
\hline 18 & $\begin{array}{l}\text { Admin memilih } \\
\text { menu data kelas RS }\end{array}$ & $\begin{array}{l}\text { Menampilkan form untuk menambah } \\
\text { dan mengedit data kelas rumah sakit }\end{array}$ & $\begin{array}{l}\text { Tampil form untuk } \\
\text { menambah dan mengedit data } \\
\text { kelas rumah sakit }\end{array}$ & Terpenuhi \\
\hline 19 & $\begin{array}{l}\text { Admin memilih } \\
\text { menu user }\end{array}$ & $\begin{array}{l}\text { Menampilkan halaman user dan } \\
\text { mengedit data operator }\end{array}$ & $\begin{array}{l}\text { Tampil halaman user dan } \\
\text { mengedit data operator }\end{array}$ & Terpenuhi \\
\hline 20 & $\begin{array}{l}\text { Admin memilih } \\
\text { menu keluar }\end{array}$ & $\begin{array}{l}\text { Menampilkan keluar dari menu } \\
\text { administrator ke halaman utama }\end{array}$ & $\begin{array}{l}\text { Tampil keluar dari menu admi- } \\
\text { nistrator ke halaman utama }\end{array}$ & Terpenuhi \\
\hline
\end{tabular}

\section{PEMBAHASAN}

Aplikasi siDARURAT didesain untuk user (pengguna) dan sudah terintegrasi dengan smartphone. Hasil pengujian black box menunjukkan interface aplikasi siDARURAT berjalan sesuai harapan, artinya aplikasi siDARURAT berguna sesuai fungsinya. Fungsi dalam sistem, baik form maupun tombol-tombol yang ada telah berjalan sesuai fungsinya berdasarkan pengujian black box.

Halaman home untuk user menunjukkan tulisan siDARURAT pada aplikasi siDARURAT adalah sebuah gambar logo dan nama dari aplikasi siDARURAT yang berfungsi sebagai loading saat aplikasi pertama kali di run, yang berfungsi untuk meload sebuah halaman webservice yang berjalan secara background dan juga berkomunikasi dengan server yang beralamat http://www.sidarurat.com/, di samping itu juga berfungsi untuk pendeteksian ada atau tidaknya jaringan internet pada perangkat smartphone, halaman home juga menunjukkan informasi ketersediaan ruang rawat dan darah di rumah sakit (Abdelhak, et al,. 2007). Halaman rumah sakit menunjukkan informasi ketersediaan ruang rawat di beberapa rumah sakit di Kabupaten Pekalongan. Halaman PMI menunjukkan informasi ketersediaan darah di UTD PMI Kabupaten Pekalongan. Halaman kuesioner menunjukkan kuesioner penilaian yang bisa diisi oleh pengguna siDARURAT.

Tampilan aplikasi siDARURAT ringan sehingga tidak membebani kinerja komputer atau handphone atau tablet. Tampilan aplikasi siDARURAT sangat fleksibel jadi bisa di instal diberbagai tipe komputer atau handphone atau tablet (Abdelhak, et al,. 2007).

Tampilan aplikasi siDARURAT menggunakan bahasa Indonesia. Bahasa sering digunakan sebagai alat komunikasi untuk menyesuaikan situasi atau kondisi agar dapat disampaikan dan dimengerti oleh lawan bicara, baik dari laras bahasa maupun kata-kata yang digunakan harus disesuaikan dengan lawan bicara agar mudah dipahami (Al-Adaileh, 2009).

User dari aplikasi ini terdiri dari tenaga kesehatan seperti dokter, perawat, bidan dan tenaga kesehatan lainnya dan juga masyarakat. Bagi tenaga kesehatan khusunya di Puskesmas yang bekerja 24 jam, ketika harus merujuk pasien seringkali sulit mendapat info cepat dimana rumah sakit yang tersedia ruang rawat tanpa harus menghubungi satu persatu rumah sakit. Beberapa kasus terjadi bahkan harus merujuk ke luar wilayah Kabupaten Pekalongan karena sulitnya mengakses informasi mengenai ketersediaan ruang rawat. Beberapa faktor penyebab masalah ini adalah "diperoleh informasi" ruang rawat yang akurat namun rumah sakit sudah penuh atau "tidak diperoleh informasi" yang akurat karena telepon sibuk, jaringan yang terganggu, dan lainlain. Pada kondisi yang mendesak misalnya gagal jantung, gagal nafas, perdarahan post partum, eklamsia atau kondisi yang mengancam nyawa lainnya petugas sangat ingin segera mendapat informasi rumah sakit yang bisa digunakan untuk merujuk dan hal itu bisa menghabiskan waktu 1 jam hanya untuk mendapat informasi akurat karena harus menghubungi rumah sakit secara manual. Hal inipun tergantung situasi dan kondisi 
PROFESI (Profesional Islam): Media Publikasi Penelitian

2019; Volume 16; No 2.

Website: ejournal.stikespku.ac.id

dan apabila terjadi pasien akan menunggu lama untuk sampai di tempat tujuan apalagi dengan kondisi yang mengancam nyawa tentu akan menimbulkan kekhawatiran tersendiri baik bagi petugas kesehatan maupun keluarganya. Selain informasi tentang ketersediaan ruang rawat, informasi tentang ketersediaan darah juga merupakan hal yang sangat penting pada kondisi kegawatdaruratan khususnya pada kasus-kasus kehilangan darah seperti kecelakaan lalu lintas, perdarahan post partum, operasi besar, keganasan dan lain-lain. Kebutuhan akan darah tidak mengenal waktu, 24 jam sehari bahkan dikala liburpun harus disiagakan, sehingga informasi terbuka akan ketersediaan darah menjadi sangat penting. Sehingga website sidarurat.com ini sangat dibutuhkan oleh tenaga kesehatan dengan "one click" dapat mendapatkan informasi yang cepat dan akurat terkait ketersediaan ruang rawat dan ketersediaan darah di Kabupaten Pekalongan sehingga dapat mempercepat penanganan pasien dengan kondisi yang mengancam nyawa. Selain tenaga kesehatan, masyarakatpun dapat menggunakan aplikasi siDARURAT ini (Al-Adaileh, 2008).

Peneliti bekerja sama dengan ketua IT di setiap rumah sakit maupun ketua Unit Donor Darah untuk selalu mengupdate data ketersediaan ruang rawat dan ketersediaan darah. Website sidarurat.com juga menyediakan fitur untuk menambah operator, sehingga operator untuk pengupdatean data juga tersebar diruang-ruang rawat inap dan unit donor darah yang bertugas mengupdate data ketersediaan ruang rawat dan ketersediaan darah setiap kali mengalami perubahan (real time) (Abdelhak, et al,. 2007).

Saat ini handphone/tablet telah mampu mengubah ketergantungan akan komputer dekstop, bukan hanya dalam hal teknologinya namun kemudahan mobilitasnya yang tinggi yang bisa menarik minat penggunanya. Dilihat dari segi dimensi perangkat tentunya orang akan lebih memilih handphone yang hanya segenggaman tangan daripada harus menjinjing PC atau laptop yang berat. Untuk melakukan tugas atau aktifitas memang lebih menguntungkan handphone daripada PC. Dilihat dari segi mobilitas dan kebutuhan sehari-hari penggunanya tentu handphone lebih mudah digunakan dan sangat user friendly di mata user. Sehingga baik tenaga kesehatan maupun masyarakat bisa mendapatkan informasi mengenai ketersediaan ruang rawat dan ketersediaan darah kapanpun dan dimanapun berada dengan menggunakan handphone/tablet (Rotrigeus, 2010).

\section{SIMPULAN}

Aplikasi siDARURAT ini dapat memberikan informasi ketersediaan ruang rawat dan ketersediaan darah di rumah sakit di Kabupaten Pekalongan dan PMI Kabupaten Pekalongan. Aplikasi siDarurat ini bersifat interaktif. Kecepatan internet memperngaruhi dalam penggunaan aplikasi ini. Aplikasi siDARURAT ini lebih sempurna apabila rumah sakit dan PMI dapat bekerjasama mengupdate data secara rutin dan tepat waktu.

\section{REFERENSI}

Abdelhak, M, Grostick, S, Hanken, M, Jacobs, E. (2007). Health Information Management of a Strategic Resource. Third edition. USA: Saunders Elsevier.

Al-adaileh, R. (2008). Essentials of Management Information Systems. Karak-Jordan: Yazeed Publications.

Al-adaileh, R. (2009). An Evaluation of Information Systems Success: A User Perspective- the Case of jordan Telecom Group. European Journal of Scientific Research Karak- Jordan. EuroJournals Publishing, Inc: 226-239

Depkes RI. (2008). Pedoman Pembinaan dan Pengawasan Pelayanan Darah oleh Dinas Kesehatan. Jakarta: Dirjen Bina Pelayanan Medik Depkes RI.

(2008). Buku Pedoman Pelayanan Transfusi Darah ; Sumbangan Darah Secara Aman. Jakarta: Depkes RI.

Kementrian Kesehatan Republik Indonesia. (2013). Buku Pegangan Sosialisasi Jaminan Kesehatan Nasional (JKN) dalam Sistem Jaminan Sosial Nasional Jakarta. Kemenkes RI. 
PROFESI (Profesional Islam): Media Publikasi Penelitian 2019; Volume 16; No 2.

Website: ejournal.stikespku.ac.id

Miah, S. J., Gammack, J., \& Hasan, N. (2017). Extending The Framework For Mobile Health Information Systems Research: A content analysis. Information Systems. 69: $1-24$.

Pai, R. R., \& Alathur, S. (2018). Assessing mobile health applications with twitter analytics. International Journal of Medical Informatics. 113: 72-84.

Sahay, S., Nielsen, P., \& Latifov, M. (2018). Grand Challenges Of Public Health: How Can Health Information Systems Support Facing Them? Health Policy and Technology. 7(1): 81-87.
Segato, F., \& Masella, C. (2017). Telemedicine services: How to make them last over time. Health Policy and Technology. 6(3): 268-278.

Setiawan, I. (2012).Masih Takut Donor Darah? Apa Kata Dunia!. Suara PMI:Palang Merah Indonesia.

Rodrigeus, J. (2010). Health Information Systems: Concepts, Methodologies, Tools, and Aplications. Volume I. New York: Medical Information Science Reference. 